ORIGINAL ARTICLE

\title{
PARENTAL PERCEPTION ABOUT WESTERN CARTOON ON CHILD'S MENTAL HEALTH IN PAKISTAN
}

\begin{abstract}
The purpose of this study is to explore the impacts of foreign cartoons programs on the social behavior and attitude of Pakistani Children. It is forecasting different cartoon programs 24/7; hence, children spend most of their leisure in front of the television. All these cartoon characters affect the social life and psyche of the children and induce positive and negative mannerism in their daily lifestyles. It has found that one of the most disturbing factor is that the ferocity in children today is increasing rapidly due to following their favorite violent cartoon characters which are even different from their culture and societal norms. The issue is violence is what they see in every cartoon program in one or the other way. Their Guardians are unaware that these cartoons they let their children watch are destroying their parenting as negative forces are attacking the innocent minds of this generation.
\end{abstract}

The study gives the insight of why and what is happening with non-parametric statistics studied and used for thorough analysis. The behavioral outcome of the kids like, imitating their preferred animation character, utilizing various dialects, watching the TV as opposed to deciding on outdoor games and being difficult about getting precisely the same outfits and embellishments as their adored character. This contextual analysis features the disturbing circumstance that guardians are uninformed of. There is something other than mimicking the particular character. The only traits of watching these foreign cartoon characters is that it might damage their own customs and they wildly become to believe these characters as their role models.

KEY WORDS: Animated TV Shows, Children, Attitude, Behavior, Cartoons, Violence, Role Model, Pediatric Mental Health

\author{
Farah Sultan \\ PR Manager \\ Edenrobe \\ farahjamil93@gmail.com \\ Zakl Hasan \\ Senior Lecturer \\ SAIMS \\ Zakihasan1234@gmail.com
}

[Sultan F. and Hasan Z. Parental Perception about Western Cartoon on Child's Mental Health in Pakistan.2020;9(2):48-53]

DOI:10.36283/pjr.zu.9.2/010 


\section{INTRODUCTION}

Children of almost any age are mostly fond of watching cartoon programs and it is seen that children in any family, their television is mostly screened cartoons and animated shows. In Pakistan, the media industry is not that much highly upgraded that they produce their own cartoons therefore it is seen that television shows and cartoon films on aired in Pakistan usually made in by foreign countries since the 60s and it have been the best source of entertainment for children over here. Felix the Cat was the first ever cartoon icon to air on television but in Pakistan it has seen that in the starting era only National Channel PTV on aired few of the cartoons like Popeye the Sailor and Pink Panther because there was no concept of cable channels in that particular era. In the later decades it came along the famous and legendary cartoon characters like Mickey Mouse, Donald Duck and Pluto which were introduced by Disney Brother' s Cartoon Studio '. It is found that in recent times, the addiction and love towards cartoons has caused children to participate less in physical activities resulting in several problems. Not likely the previous generation; people who use to play sports, follow physical activities as a source of entertainment, children today prefer staying at home and watching television. Whether they put resources into their kids' instruction or not, Pakistani families, paying little mind to their social class do put resources into a TV when they can. Stroll into a Pakistani home on some random night and you're probably going to run over whole families stuck to the screen, viewing the most recent quarrel between politicians - the nature of which is arriving at new lows as far as language and the degree of antagonism and outrage being shown. That or it will be the most recent TV show including a man conflicted between two sobbing spouses, which appear to be standard nearby amusement for most families. What is prominent by its nonattendance on neighborhood TV slots is quality programming for youngsters that is socially important ${ }^{2}$.

Only one channel which is being globally known, Cartoon Network is one of the most favorite channel known among the children. Cartoon Network came to life in 1992 and quickly made its way to every child's heart. It has undoubtedly gained record-breaking fame. To be precise Since August 2002, CN has been watched across 80 million homes in United States of America alone and furthermore in 145 countries in the world and in Pakistan it is seen since 2004.

Thirty-five percent of the Pakistani populace is under 15 years of age, yet the promoting spend on them is only three percent which for the most part winds up with Nickelodeon and Cartoon Network. Also, both these channels are utilizing instant substance with effectively conspicuous characters, which requires little as far as promoting. PTV is accomplishing some work here yet they are obliged to as an administration run channel. For example, it contains violence more than comedy and fun, almost as if it's a promotion of one ${ }^{3}$. This has resulted in children becoming more exposed and vulnerable to violence at an age yet tender ${ }^{4}$.

The effects and behavioral changes in Pakistani Children who watch Cartoon Network on regular routine has been one of the significant issue found ${ }^{5}$. In this specific examination, the researcher is attempting to discover the effects and impacts of these foreign cartoons on youngsters of Pakistan as they are truly affecting their standard conduct and its changes 6 .

The objective of this study is to highlight the factors which effected by Cartoon Network in Pakistani Children ${ }^{7}$. This is to underline the impact of those factors on children and how each factor has emerged as a direct cause of ill-behavior, negative influence and health complications amongst children of a tender agers of Pakistan. Childhood is a fragile part of life that needs to be dealt with delicacy and observance ${ }^{8}$. Therefore, the main focus of this report is to make sure no child undergoes such circumstances that leads him to a path of violence, negative effects on norms and cultures of Pakistan, unhealthy habits and complications and as well as a wrong perspective of life?

These animated series are supposed to follow all cultural norms, no matter for which country it is from, also it should consist nil percentage of violence, negativity and any sort of negative influence that may affect a child later on in life. It has been observed and reported several times that cartoons have been a major factor in a child's lack of performing skills ${ }^{10}$. The followers and addiction of cartoons, not to forget how CN is available 24/7, has caused children to face improper sleep, improper diet and an inactive lifestyle and most importantly negligence of their own country norms 11.

The purpose of this study is to find that how these foreign cartoons are effecting social and cultural behaviors of children in Pakistan. It has seen in previous researches that cartoon network has changing the attitude and personality of children, changing the mindset of cultures among children on this basis the researcher is trying to extract the impact on behavior, attitude and personality of children while and after watching various series ${ }^{12}$. Kid's shows are an inescapable piece of each kid's life. Since the rise of animation films longer than a century prior, a few ages of youngsters have grown up watching vivified films ${ }^{13}$. A large number of young ladies have fantasized about being princesses and young men 
have envisioned themselves to be brave knights in the wake of watching exemplary energized stories like Peter Pan, Aladdin and the Magic Lamp, Cinderella, Beauty and the Beast, and so forth ${ }^{14}$.

Youngsters regularly draw solid strict and otherworldly mental symbolism and thoughts from kids' films and kid's shows, for example, The Lion King, which subject spins around the strict convictions and practices of African animism. "Hercules" is an another illustration of a youngsters' film that draws intensely on strict components, just as Aladdin, to a limited degree, mixing fantasy, strict follows, and sentiment ${ }^{15}$. The point is to discover the connection and effect of these kid's shows on youngsters' conduct ${ }^{14}$. Through this investigation, youngsters and guardians improve picture and reason of social changes and by this they can beat the negative results. The exploration is restricted to the market of Pakistan and it has numerous imperatives including time, account and lacking sources ${ }^{16}$.

In this report, we will cover how incredibly delicate an adolescence is, to later reveal insight into the significance of monitoring the negative effect of animation arrange on kids. The point of this report is to not just guarantee that no point, factor, region or cause is abandoned yet additionally to provide peruses a legitimate guidance on where to lead from that point ${ }^{17}$.

Youngsters are earth to encounters and presentation, they form into what they have been opened up to. Hence, it is profoundly fundamental for one to know about the negative impact kid's shows have on kids in detail to guarantee the youngsters encompassing them are protected from its results ${ }^{18}$. It was noticed that male youngsters were affected by brutality arranged kid's shows more than female kids, and that they imitated animation characters more ${ }^{19}$. Negative impact doesn't show itself unexpectedly, it steadily develops over the surface until one day, it just breaks the ice. Consequently, the importance of this investigation is viewed as high ${ }^{20}$.

This study has been all around explored, comprehended and examined before being recorded on paper. Each point has been altogether concentrated with realities to help it ${ }^{21}$. The time kids spend before the TV today has expanded for different reasons. Hardware has become a piece of our lives. At the point when a youngster is conceived, it resembles a vacant scratch pad ${ }^{22}$. It's what we compose there that makes their future. Thus, it's up to us, their folks to be their educators and the climate where they are living, to instruct them to turn out to be better people ${ }^{23}$. It's vital, for the youngsters between the age of $3-6$ years which are excessively little, to open them to the cherishing and caring climate ${ }^{24}$. In the current world, advanced media are unavoidable by each age gathering of kids along with a better language contact to understand various cultures ${ }^{25}$.

\section{METHODOLOGY}

In this research the researcher has used Descriptive Research Design to explain the effects of various children who watch foreign cartoons in Pakistan. Content analysis research tool is being used. In content analysis research tool, the actual content of various cartoons has been taken and each of them has been thoroughly analyzed for each of the research questions and their variables. The analyst has assembled the information from different parents and kids in Pakistan. The populace must have the fundamental comprehension of results into the kids who watch foreign cartoons organize every day that is the reason the specialist has led the investigation from their parents. Additionally, different kids have been watched while watching foreign cartoons, to take note of their practices.

\section{Sample Size}

Open EPI calculator was used to calculate sample size. Therefore, considering $80 \%$ confidence interval and $9 \%$ absolute precession percentage the sample size of $n=51$ was calculated.

\section{Sampling Technique}

Non Probability convenience sampling technique.

\section{Data Collection}

A qualitative study has been conducted through two channels i.e. questionnaire and observation to investigate the variables based on different experiments. This particular research observes the multiple outcomes of interest without changing the actual conditions. On the basis of various images and videos, the interpretive thoughts have been concluded to provide the true image of the results.

\section{Inclusion Criteria}

- Both male and female parents.

- Parents whose children are young and watches cartoon

\section{Exclusion Criteria}

- Adult Children Parents

- Children who do not watch cartoon

\section{Data Analysis}

To examine the information and other exploration data, interpretive examination results has been finished up based on different contemplations and various respondents. Numerous human responses have been molded by accommodating the pictures and recordings of animation characters. Different inquiries have been posed to respondents and their parents to look at the outcomes.

In addition; researcher utilized elucidating measure- 
ments is utilized on the grounds that it gives fundamental investigation of the examination. It gives rundowns of the segment test age, sexual orientation and instruction. To check the impact of factors among one another, it is bound to interpretive examination of different recordings and pictures. Every one of these strategies have been arranged and tweaked intelligently just to make the results progressively clear and applicable.

\section{Ethical Considerations}

All the individuals were assured that their identity and obtained information was kept confidential under the supervision of researcher. The participants were respected and were seen as a positive source to be the part of this research. Before the commencement of the study the consent form is being provided to every participant in order to make them aware about possible risks and benefit.

\section{RESULTS}

The purpose behind this investigation is to see the effect of kid's shows on the conduct of youngsters. In this particular study, researcher have posed different inquiries to different youngsters and their guardians. Besides, scarcely any photos and recordings have been appeared to the youngsters just to record their responses and their mental responses.

The first basic question which have been asked to the kids is their preferred animation appear, which infers that larger part of the kids love to watch Tom and Jerry, Dorremon and Ben 10.Figure 1.

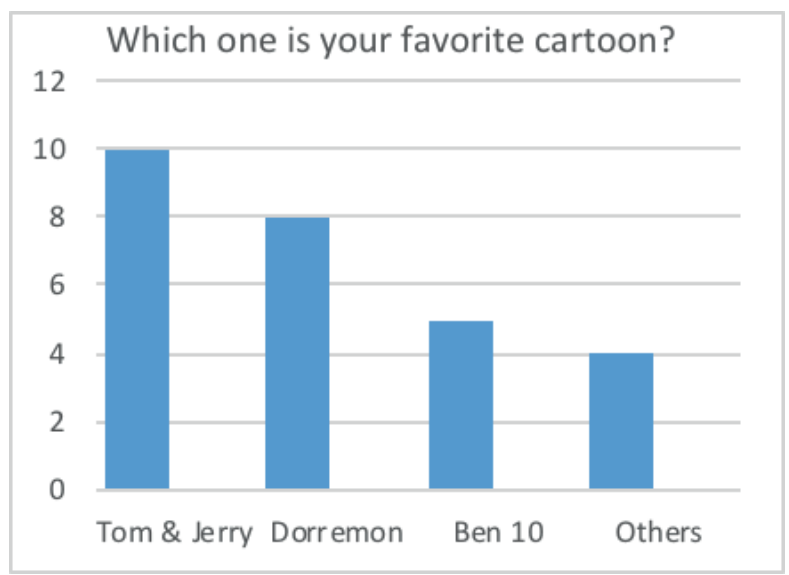

Figure.1: Analysis 1

Usually children spend approximately 3 to 4 hours of their day watching cartoons and some of them spend more than 4 hours watching cartoons. This results have been concluded when the researcher asked children' parents that how much time do they spend on watching cartoons figure 2.

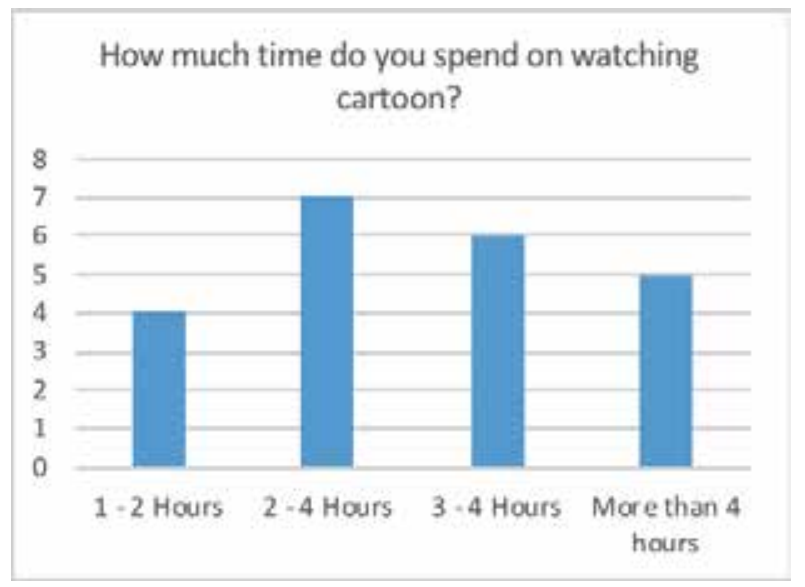

The third question which is being met to the guardians is to get some information about the mental consequences for their youngsters when watching the animation. Greater part of the guardians has addressed that they have seen a reasonable change in the demonstrations and mind of their children when watching cartoons. Normally they get include in the animation and considerably in the wake of watching these characters, they didn't receive in return and go about according to their preferred cartoon characters.

The conduct of youngsters which have been seen in the wake of watching animation has changed. Larger part of the kids acts uniquely in contrast to their every day schedule. They give more consideration to the whole story of the arrangement and they have a fever on explicit character which truly changes the manner in which they carry on in the ordinary life.

Another question which is being posed to the guardians that do their youngsters expect to hint their language according to animation character or their demonstrations are like them? The reaction is actually what we have watched. Kids change their language and acts, even they take in the language and discoursed from their optimal characters and continue rehashing them the entire day along. They even attempt to duplicate their demonstrations and activities which in some cases disturb their folks and others around. Most of them are against the norms and cultures of Pakistan even though they love to watch these characters and try to attempt their acts in their daily routine of life.

\section{DISCUSSION}

It has likewise been seen that understudies for the most part incline toward watching kid's shows instead of going out and mess around. Indeed, even they continue watching arrangement in their leisure time, noon and evening. They acquire diversion watching kid's shows separated from physical games. In addition, the researcher observed that 
many of the cartoons shows the cultures which are against the norms of Pakistan and usually misguides our children and enforces them to follow them.

It is observed that pictures that the acts and scenes reflects all those cultures which is not being followed Pakistan on regular basis. As shown to the respondents in various figures and images, it is concluded that Tom \& Jerry is celebrating Christmas and receiving gifts from Santa Claus, by watching these acts the children of Pakistan also demands to receive gifts from Santa Claus and ask their parents to arrange it for them. In another picture, in other image shown to respondents, it is seen that mickey mouse and Minnie is kissing which is also not a common act in Pakistan and explicit thing for children. Following the previous image, Figure 6 also shows the western dressing concept which is also vague and unacceptable in Pakistan and usually parents do not allow their children to watch such shows.

\section{CONCLUSION}

The outcomes of this research has broken down the various perspectives that the lead of kids changes while watching the foreign cartoons. In this investigation it has found that those children who watches cartoons more than 3 hours' sort out, contrarily influence children's temper and direct. All of the assessments, gatherings and discernments which have been driven in this paper has found that the psychological effects on children's insights are changing their direct.

The arrangement which demonstrated the violence as far as activities and fight results that kids get respond contrarily as far as motions, dialects, acts and their mind. It is seen that in the period of learning, the things and activities youngsters are embracing contrarily building up their character. Something else which have been deduced in this examination that kids admires diverse animation character while they watch arrangement. These cartoons also affect their social and cultural norms which are being directly hit because all these foreign characters show the western cultures and the children of Pakistan follows them as because approximately three to four hours of their day (which is almost 1/4th part of their day) spent in watching these cartoons.

\section{ACKNOWLEDGEMENT}

I would like to acknowledge my family who played very important role in my academic accomplishments. First of all, my parents and my wife who always supported me with their love and prayers. Secondly, all my mentors who provided me additional guidance throughout my career.

\section{REFERENCES}

[1] Afzal H, labal Z. Representation of Pakistan's International Issues Through Newspaper Cartoons: A Semiotic Analysis. EJELLS 2018(3).

[2] Ashfaq A, ljaz S, Shami S. Drawing the Foreign Rivalry: Depiction of Indo-Pak Relations in Political Cartoons of Mainstream Pakistani and Indian English Newspapers (2014-2017). Global Regional Review. 2019;4(1):8-20.

[3] Cooper-Chen A. Cartoon planet: the cross-cultural acceptance of Japanese animation. Asian J.2012;22(1):44-57.

[4] Hassan A, Daniyal M. Cartoon network and its impact on behavior of school going children: a case study of Bahawalpur, Pakistan. (IJMESS). 2013;2(1):6-11.

[5] Inan G, Inal S. The impact of 3 different distraction techniques on the pain and anxiety levels of children during venipuncture. Clin J Pain2019;35(2):140-7.

[6] Lakho MK, Mangrio QF, Khalil H, Fazal A. FOREIGN ELECTRONIC MEDIA AS A SOURCE OF CULTURAL DIFFUSION: A THEMATIC STUDY OF ITS IMPACTS ON CULTURE OF SINDH, PAKISTAN. J. Soc. Media Stud. 2017;1 (2):9-17.

[7] Lokanathan V. Danish Cartoons: Reactions in India, Pakistan and Bangladesh. Institute of Peace and Conflict Studies. 2006 (1965):1-2.

[8] Naz S, Rasheed M, Rasheed T. Effects of Hindi Dubbed Cartoons on Students' Linguistic Patterns and Culture. Global Language Review. 2018;3(1):126-35.

[9] Zaheen B, Khan MA. Children, Gender and Television: An Analysis of Heavy Viewers' Behaviour Regarding Gender-specific Roles and Characteristics. Global Regional Review. 2019:4(2):364-74.

[10] Okada Y, Wu D, Trynka G, Raj T, Terao C, Ikari K, Kochi Y, Ohmura K, Suzuki A, Yoshida S, Graham RR. Genetics of rheumatoid arthritis contributes to biology and drug discovery. Nature. 2014;506(7488):376-81.

[11] Rawan B, Dar M, Siraj SA. Televised Cartoons and Incidental Learning of Foreign Language among Children: A Case Study of Doraemon Cartoon in Pakistan. Pak. j. distance online learn.2018;4(1):95-110.

[12] Raza S, Awan S, Gondal S. What are Your Children Watching? Teacher's Evaluation of the Educational, Emotional, Behavioral, Psychological, Physical \& Religious Impacts of Cartoons on the School Going Children. Teacher's Evaluation of the Educational, Emotional, Behavioral, Psychological, Physical \& Religious Impacts of Cartoons on the School Going Children. 2016:39-45.

[13] Rosset DB, Santos A, Da Fonseca D, Poinso F, O'Connor K, Deruelle C. Do children perceive features of real and cartoon faces in the same way? Evidence from typical development and 
autism. J. Clin. Exp.. $2010 ; 32(2): 212-8$.

[14] Jin $Y$, Jiang W, Wenxin WU, Wenlian YE, Jiang A. Effect of cartoon video-assisted preoperative interview on postoperative maladaptive behaviors of preschool pediatric patients. Chinese Journal of Anesthesiology. 2017;37(1):30-3.

[15] Zareen C. Influence of Hindi Dubbed Cartoons on the Linguistic Repertoire of Urdu/English Bilingual Children (Doctoral dissertation, University of Management and Technology Lahore)2017.

[16] Raza S, Gondal S. Impacts of cartoons viewing on the school going kids: Is Really a Trouble to contemplate. Available at SSRN 2827091. 201620.

[17] Mohanambigai R. A study on television viewing habits and its relationship with obesity, mental health and academic performance in school children in Tamilnadu (Doctoral dissertation, Coimbatore Medical College, Coimbatore) 2015.

[18] Wilkinson JL, Strickling K, Payne HE, Jensen KC, West JH. Evaluation of diet-related infographics on Pinterest for use of behavior change theories: a content analysis. JMIR mHealth and uHealth. 2016:4(4):e133.

[19] Ergün S. The influence of violent TV cartoons watched by school children in Turkey. Acta
Paulista de Enfermagem. 2012;25(SPE2):134-9.

[20] Kuta C. The Negative Impact of Excessive Screen Time on Language Development in Children Under 6-Years-Old: An Integrative Review with Screen Time Reduction Toolkit and Presentation for Outpatient Pediatric and Family Health Providers 2017.

[21] Hassan A, Daniyal M. Cartoon network and its impact on behavior of school going children: a case study of Bahawalpur, Pakistan. International Journal of Management, Economics and Social Sciences (IJMESS). 2013;2(1):6-11.

[22] Kukreja J. Cartoons Cast an Eternal Impact on Personalities: Effects of Cartoons on Children. InHandbook of Research on Children's Consumption of Digital Media 2019 (pp. 369-379). IGI Global.

[23] Ghilzai SA, Alam R, Ahmad Z, Shaukat A, Noor SS. Impact of Cartoon Programs on Children's Language and Behavior. Insights in Language Society Culture (2). 2017:104-26.

[24] Lodhi MA, Ibrar SN, Shamim M, Naz S. Linguistic Analysis of Selected TV Cartoons and Its Impact on Language Learning. IJEL. 2018;8(5):247.

[25] TEMIZYÜREK $F$, Ümran AC. The Impact of Subliminal Messages in Cartoons on Children. Cumhuriyet Uluslararası Eğitim Dergisi. $2014 ; 3(3): 25-39$. 